\title{
PENINJAUAN POSTER DARI WARNA DAN TIPOGRAFI DI SMK MULTIMEDIA ISTIQLAL
}

\author{
Muhammad Bagus Supandi ${ }^{1 *}$, Adek Cerah Kurnia Azis ${ }^{2 *}$ \\ Program Studi Pendidikan Seni Rupa Jurusan Seni Rupa Fakultas Bahasa dan Seni \\ Universitas Negeri Medan \\ Jl. Willem Iskandar Pasar V Medan Estate, Kec, Percut Sei Tuan, Kab. Deli Serdang, Kode Pos 20371 \\ Sumatera Utara. Indonesia \\ Email:bagussupandi8@gmail.com,adek_peros@yahoo.com
}

\begin{abstract}
Abstrak
Penelitian ini bertujuan untuk mengetahui hasil kary a poster ditinjau dari warna, tipografi dan komposisi sis wa kelas X SMK Multimedia deli tua. Populasi dalam penelitian ini adalah seluruh siswa kelas X SMK Multimedia Istiqlal Deli Tua yang terdiri dari 4 kelas dengan jumlah sis wa 140 orang. Sampel dalam penelitian ini diambil dengan teknik cluster random sampling (acak kelas), maka diperoleh sampel berjumlah 5 orang. Teknik pengumpulan data melalui observasi dan dokumentasi. Data yang terkumpul dianalis is dengan teknik deskriptif kualitiatif dan diwujudkan dalam bentuk tabel. Hasil temuan penelitian menunjukkan bahwahasil karya pos ter ditinjau dari warna, tipografi, dan komposisi baik. Dari kategori di atas, dapat disimpulkan bahwa hasil kemampuan sis wa dalam membuat karya poster tergolong baik.
\end{abstract}

Kata Kunci: analis is, warna, tipografi.

\begin{abstract}
This study aims to determine the results of the poster's work in terms of color, typography and composition of all students' class X vocational high school multimediadeli tua. The population in this study were all students of class $x$ vocational high school multimedia istiqlal Deli Tua which consisted of 4 classes with a total of 140 students. The sample in this study was taken by using cluster random sampling technique (random class), then the sample obtained was 20 people. data collection techniques through observation and documentation. The collected data were analyzed using qualitative descriptive techniques and represented in the form of a table. The results of the research finding indicate that the poster works in terms of color, typography, and composition was good. From the categories above, it can be concluded that the results of students' abilities in making poster work are classified as good.
\end{abstract}

Keywords: analysis, color, typography.

\section{PENDAHULUAN}

Perkembangann pendidikan di Negara yang sedang berkembang sangat diperlukan, karena pendidikan harus berjalan dengan perkembangan ilmu pengetahuan dan teknologi yang sangat pesat. Salah satu cara untuk menghadapi hal tersebut adalah dengan meningkatkan kualitas sumber daya manusia melalui bidang pendidikan, karena melalui pendidikan segala potensi yang ada dalam diri manusia dapat dibina dan dikembangkan. Pendidikan merupakan usaha agar manusia dapat mengembangkan potensi dirinya melalui belajar. Menurut UUD No. 20 Tahun 2003 tentang Pendidikan Nasional disebutkan Pendidikan Nasional berfungsi mengembangkan kemampuan dan watak serta peradaban bangsa yang bermartabat dalam rangka mencerdaskan kehidupan bangsa.

Selaras dengan kebijakan pembangunan pendidikan yang meletakkan pembangunan sumber daya manusia sebagai prioritas pembangunan nasional, maka kedudukan guru semakin strategis dalam mempersiapkan sumberdayamanu sia yang berkualitas, dalam upaya peningkatan mutu pendidikan tingkat SD, SMP, SMA/SMK, menghadapi era milenial. Pada SMK Istiqla Deli Tua terdapat mata pelajaran Seni Rupa yang didalamnya terdapat pelajaran poster. Sekolah melatih peserta didik untuk membuat poster. Tema poster tidak ditentukan oleh guru, dengan kata lain poster pesertadidikbebas memakai tema apa saja. Seperti pendidikan, lingkungan serta kesehtan.

Pada dasarnya pengetahuan peserta didik tentang membuat poster masih sangat minim. pengetahuan peserta didik tentang warna pada poster sangat kurang. Terlihat dari karya peserta didik tentang poster masih kurang baik dimana komposisi, serta tipografinya belumtepat, sehingga karya tidak menarik, sepertinya 


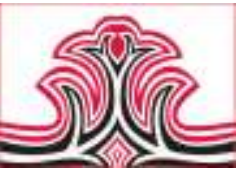

Peserta didik belum mampu men erapka prins ip-prinsip desain pada poster.

Penyampaian informasi dan komunikasi menjadi sangat penting, ketika manusia mengutarakan maksud, ide, atau tujuannya. Pengembangan tekhnologi yang pesat dipengaruhi oleh perkembangan ilmu pengetahuan yang melahirkan media cetak sebagai alat penyampaian pesan, untuk mendapatkan informasi yang lebih cepat dan praktis. Salah satunya adalah karya seni poster atau desain grafis yang memuat kompos isigambar, huruf di atas kertas dan kes elarasan warna.

\section{KAJIAN TEORI}

Penelitian ini menggunakan sumber referensi yang relevan sebagai refesensi dan perbandingan agar memperkuat gagasan dan konsep dalamarikel. Sumber referensi yang dijadikan sebagai refensi yaitu yang berjudul: "Poster Pariwisata Di Kabupaten Samosir Ditinjau Dari Disharmoni Warna, Tipografi Dan Layout Dengan Prinsip-Prinsip Desain Poster".

Poster adalah seni grafis yang telah ada sejak abad 15 sebagai sarana untuk menyampaikan informasi dan pariwara. Pengumuman pemerintah kepada rakyatnya, penobatan raja, hing ga iklan pedagang yang berpindahpindah. Awalnya Poster memang hanya berisi teks saja. Baru sejak akhir abad 17 muncul poster bergambar. Namun dewasa ini poster juga dimanfaatkan sebagai sarana eks presi seni menggunakan tatanan aksara yang sangat menarik dan kreatif.

Menurut Wisnu(2012: 1). "Poster sendiri didefinisikan sebagai gambar pada selembar kertas berukuran besar yang digantung atau ditempel di dinding atau permukaan lain. Poster merupakan alat untuk mengiklankan sesuatu, sebag ai alat propag anda, protes, serta maksud-maksud lain untuk menyampaikan berbagai pesan." Membuat sebuah poster tidak lepas dengan apa yang dis ebut dengan menggambar, karena semua itu berawal dari menggambar dimana menggambar adalah suatu kegiatan atau proses dalam menciptakan karya visual seni rupa dua dimensi. Seperti halnya menggoreskan pensil, krayon, dan sebagainya di atas media berupa kertas, kanvas, dan lain-lain (Halawa, 2020: 194).

Menurut Wibowo (2013: 25) "Poster adalah gambar pada selembar kertas berukuran besar yang digantung atau ditempel di dinding atau permukaan lain. Poster merupakan alat untuk mengiklannkan sesuatu, sebagai alat propag anda, dan protes, serta maks ud-maksud lain untuk menyampaikan berbagai pesan. Selain itu, poster juga dipergunakan secara perorangan sebagai sarana
Gorga : Jurnal Seni Rupa

Volume 09 Nomor 02 Juli-Desember 2020

p-ISSN: 2301-5942 | e-ISSN: 2580-2380

dekorasi yang murah meriah terutama bagi anak muda."

Menurut Kusrianto(2008: 49) Poster merupakan karya seni yang tergolong dalam seni pakai yang berfungsimenunjang sarana promosi barang atau jasa termasuk untuk propag andaide-ide. Poster berbentuk 2 dimensi, biasanya bergambar dan dicetak sebanyak mungkin serta biasanya memakai bahan kertas, dan anamel.

Pada dasarnya pengetahuan peserta didik tentang membuat poster masih dapat dikatakan umum. pengetahuan peserta didik dalam pengolahan wama s angat kurang. Terlihat darikarya pesertadidik tentang poster masih kurang baik dimana komposisi, serta susunan tipografi belum tepat, sehing ga karya tidak menarik seperti Pes erta didik belummampu menerapka prinsip-prinsip desain pada poster.

Pada awalnya poster ditulis di atas panel kayu dan tembok di Yunani dan Italia. Sejarah poster dari revolusi besar pengembangan teknik percetakan yang memungkinkan untuk produksi massal dan murah dengan teknik litografi.

Teknik tersebut diciptakan oleh Senefelder Alois di Jerman pada tahun 1796. Berdasarkan gayanya poster dicetak dengan menonjolkan kreativitas desain grafisnya. Desain adalah suatu disiplin yang mengeksplorasi efek visual dan berkaitan dengan aspek luar yang dapat mempengaruhi metode dan strategi, baik kultural sosial, filos ofi, teknik dan bisnis.

Keselarasan dalam desain merupakan pembentukan unsur-unsur keseimbangan, keteraturan, kesatuan, dan perpaduan yang masing-masing saling mengisi dan menimbang. Kesebandingan atau proporsi merupakan hubungan perbandingan antara bagian dengan bagian lain atau bagian dengan elemen keseluruhan.

\section{METODE PENELITIAN}

Penelitian yang berjudul "Analisis Hasil Karya Poster Ditinjau Dari Warna, dan Tipografi Pada Karya Siswa Multimedia IstiqlalDelitua", Teknik analis is data yang digunakan dalam penelitian ini adalah teknik analisis deskriptif kualitatif yaitu mengumpulkan data informasi secara fakta yang diperoleh melalui hasil wawancara selanjutnya mengklasifikasi data yang penting dan penyusunan dilakukan secara sistematis. Teknik pengumpulan data yang digunakan adalah observasi lapangan, dokumentasi, studi pustaka, dan wawancara. 


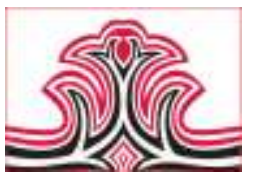

\section{HASIL DAN PEMBAHASAN}

\section{Hasil}

Berdasarkan hasil observasi dan pengumpulan data yang terlah dilakukan pada karya poster siswa SMK Multimedia Istiqlal Delitua, kemampuan sis wa dalam menggambar dan mewarnai karya poster tergolong baik, sis wa mampu memvisualisasikan imajinatif lewat sapuan kuas ke dalam bidang kertas dalam bentuk gambar poster. Pada aspek kemampuan sis wa dalam penerapan tipografi pada karya poster tergolong baik, sis wa mampu mengaplikasikan tulisan dalam poster dengan cukup baik, rapih, dan mudah dimengertioleh orang yang membacanya sehingga pesannya ters ampaikan dengan baik.

\section{1). Karya Hari Suanda}

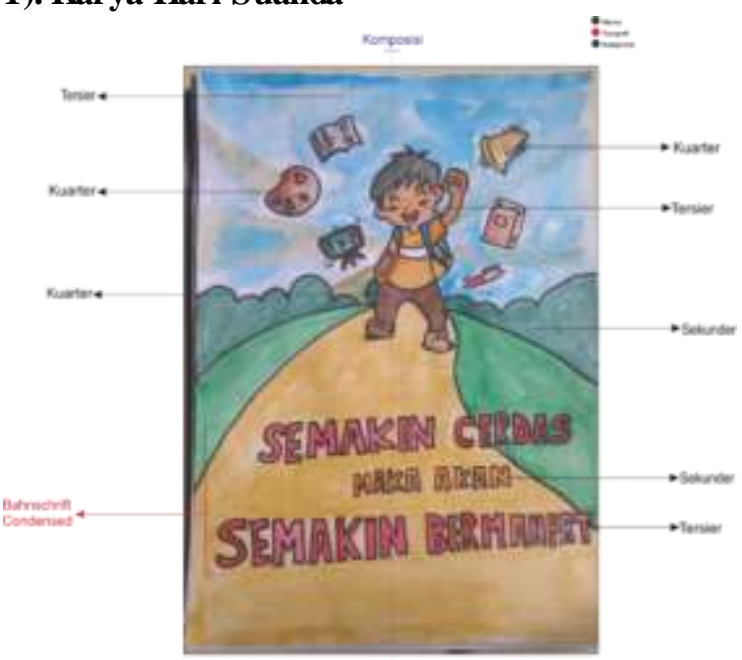

Gambar 1. Poster Semakin Cerdas Maka Akan Semakin Bermanfaat

(Supandi, 2020)

\section{2). Karya Muhammad Rendi Akbar}

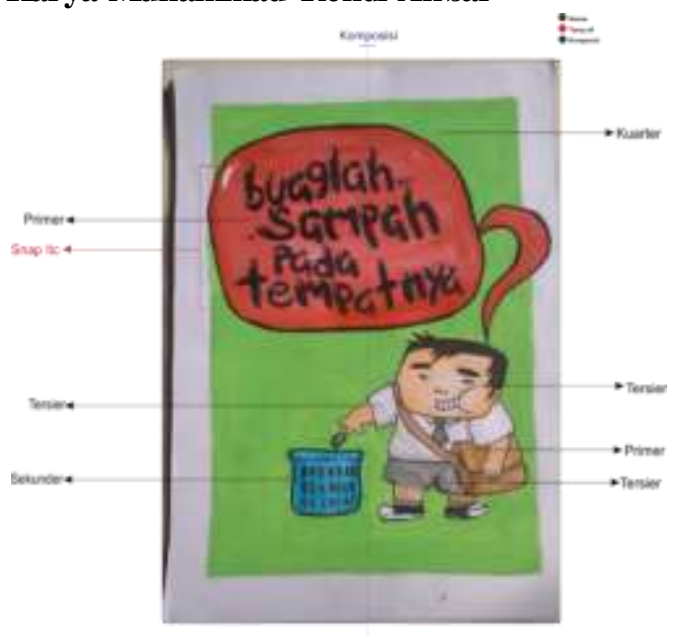

Gambar 2. Poster Buanglah Sampah pada Tempatnya (Supandi, 2020)
Gorga : Jurnal Seni Rupa

Volume 09 Nomor 02 Juli-Desember 2020 p-ISSN: 2301-5942 | e-ISSN: 2580-2380

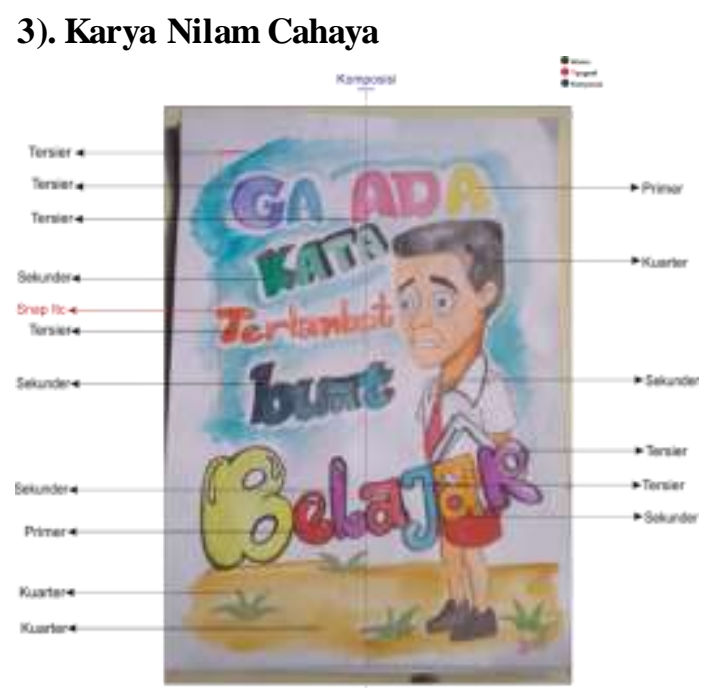

Gambar 3. Poster Ga Ada Kaya Terlambat Buat Belajar (Supandi, 2020)

\section{4). Karya Zaidan Rizky Al Aziz}

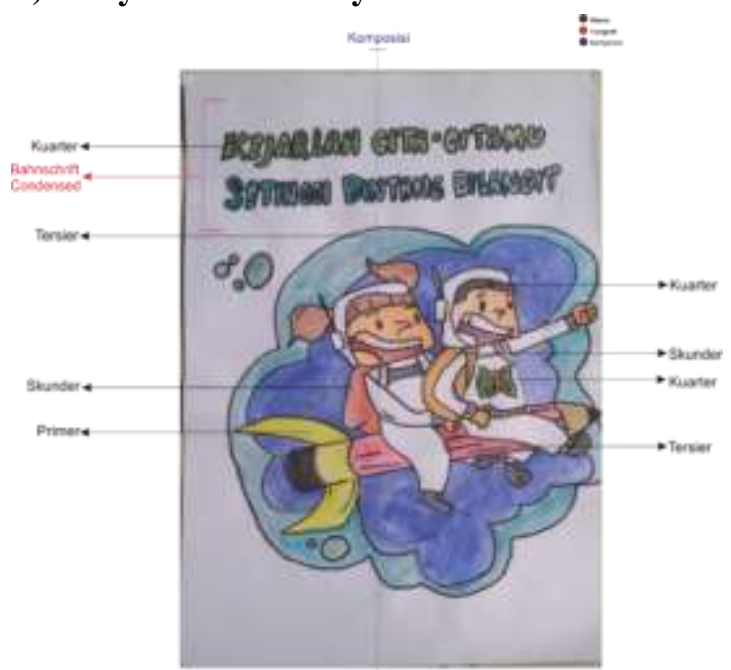

Gambar 4. Poster Kejarlah Cita-Citamu Setinggi Bintang di Langit (Supandi, 2020)

\section{5). Karya Vingka Diana}

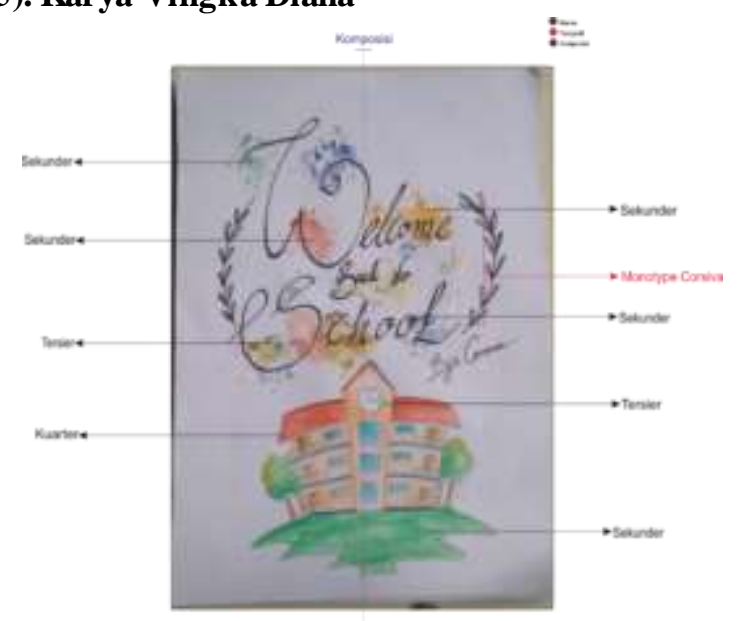

Gambar 5. Poster Welcome Back to School (Supandi, 2020) 


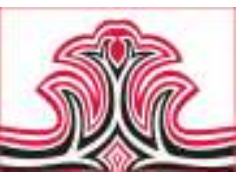

2.Pembahas an

\section{1). Hari Suanda}

Karya poster Hari Suanda adalah Poster layanan masyarakat, yaitu poster yang berisi pesan, informasi dan penjelasan yang tujuannya untuk menyadarkan masyarakat tentang suatu hal yang mengangkat kepentingan bersama. Misalnya, poster lingkungan, pendidikan, kesehatan, dan sebagainya. Dalam karya poster tersebut dapat diartikan bahwa ilmu pengetahuan sangatlah penting bagi kelangsungan hidup individu manusia. Kita hidup di jaman dimana manusia berlomba-lomba mengasah kemampuan intelektualitas demi mendapatkan kehidupan yang layak. Kelayakan hidup dapat diukur berdasarkan seberapa luas jangkauan analis is nya.

\section{(1). Warna dan Tipografi}

Dari hasil penilaian tentang warna, dapat dikateg orikan sangat baik dengan perolehan nilai 90. Dikatakan sangat baik karena warna yang di gunakan sangat merepresentasikan warna rumput, langit, dan jalan dengan sangat baik. begitu juga dengan warna pada gambar manusia yang cukup sesuai dengan as linya sehingga terlihat menarik untuk dijadikan sebagai poster. Warna yang digunakan pada huruf jug a terlihat jelas dan tegas. Dari hasil penilaian tentang tipografi, dapat dikategorikan baik dengan perolehan nilai 85 . Tipografi pada karya poster HariSuanda menggunakan klasifikasi jenis font terdiri dari Bahnschrift Condensed.

\section{2). Muhammad Rendi Akbar}

Karya poster Muhammad Rendi Akbar adalah Poster layanan masyarakat, yaitu poster yang berisi pesan, informasi, dan penjelasan yang tujuannya untuk menyadarkan masyarakat tentang suatu hal yang mengangkat kepentingan bersama. Misalnya, poster lingkungan, pendidikan, kesehatan, dan sebagainya. Karya poster ters ebut dapat diartikan bahwa kesadaran manusia dalam menjaga lingkungan masih tergolong rendah, karena walaupun sudah disediakan tempat sampah, manusia tetap saja membuang sampah sembarangan. Maka dari itu tujuan poster ini adalah hendaknya kita lebih peka terhadap lingkungan sekitar, hal paling mendas ar adalah dengan membuang sampah pada tempatnya.

\section{(1). Warna dan Tipografi}

Dari hasilpenilaian tentang warna, dapatdikategorikan sangat baik dengan perolehan nilai 90. Dikatakan sangat baik karena warna yang di gunakan sangat sesuai dengan konsep dan suasananya. Karakter pada warna karya ters ebutterlihat seperti komik, dilihat dari warna kulit, background, dan tulis annya, semua terlihat
Gorga : Jurnal Seni Rupa

Volume 09 Nomor 02 Juli-Desember 2020

p-ISSN: 2301-5942 | e-ISSN: 2580-2380

seirama, tidak saling mendominasi dan sesuai dengan tema pada karya poster tersebut. Dari hasil penilaian tentang tipografi, dapat dikategorikan sangat baik dengan perolehan nilai 90 . Tipografi pada karya poster Muhammad Rendi Akbar menggunakan klasifikasi jenis font terdiri dari Snap Itc.

\section{3). Nilam Cahaya}

Karya poster Nilam Cahaya adalah Poster layanan mas yarakat, yaitu poster y ang berisi pes an, informasi, dan penjelasan yang tujuannya untuk menyadarkan masyarakat tentang suatu hal yang mengangkat kepentingan bersama. Misalnya, poster lingkungan, pendidikan, kesehatan, dan sebagainya. Pada karya poster tersebut dapat diartikan bahwa pendidikan di negara indonesia ini sangat penting untuk kehidupan y ang lebih baik di kemudian hari. Kekhawatiran akan masa depan akan dapat dilalui seiring berjalannya waktu dan bertambahnya usia, sebelum menghadapi masa itu, lebih baik fokus pada pendidikan terlebih dahulu.

\section{(1). Warna dan Tipografi}

Dari hasil penilaian tentang warna, dapat dikategorikan sangat baik dengan perolehan nilai 90. Dikatakan sangat baik karena warna yang di gunakan sangat sesuai dengan konsep dan suasananya. Karakter pada warna kary a tersebut terlihat seperti komik, dilihat dari warna kulit, background, dan tulis annya, semua terlihat seirama, tidak saling mendominasi dan sesuai dengan tema pada karya poster tersebut. Dari hasil penilaian tentang tipografi, dapat dikategorikan sangat baik dengan perolehan nilai 90 . Tipografi pada karya poster Nilam Cahaya menggunakan klasifikasi jenis font terdiri dari Snap Itc.

\section{4). Zaidan Rizky Al Aziz}

Karya poster Zaidan Rizki Al Aziz adalah Poster layanan masyarakat, yaitu poster yang berisi pesan, informasi, dan penjelasan yang tujuannya untuk menyadarkan masyarakat tentang suatu hal yang mengangkat kepentingan bersama. Misalnya, poster lingkungan, pendidikan, kesehatan, dan sebagainya. Poster ini dapat diartikan sebagai acuan atau motivasi dalam meraih cita-cita. Cita-cita hanya sekedar anganangan jika tidak diirin gi dengan niat, usaha, dan belajar, agar dapat meraihnya. Jadi alangkah lebih baik jika kita membekali diri dengan ilmu pengetahuan terlebih dahulu supaya dapat meraih cita-cita.

\section{(1). Warna dan Tipografi}

Dari hasil penilaian tentang warna, dapat dikategorikan sangat baik dengan perolehan nilai 90. Dikatakan sangat baik karena warna yang di gunakan sangat 


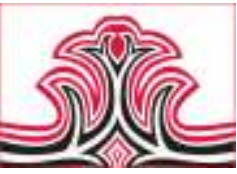

sesuai dengan konsep dan suasananya. Karakter pada warna karya ters ebut terlihat seperti komik, dilihat dari warna kulit, background, dan tulis annya, semua terlihat seirama, tidak saling mendominasi dan sesuai dengan tema pada karya poster tersebut. Dari hasil penilaian tentang tipografi, dapat dikategorikan sangat baik dengan perolehan nilai92. Tipografi pada karya poster Zaidan Rizki Al Aziz menggunakan klasifikasi jen is font terdiri dari Bahnschrift Condensed.

\section{5). Vingka Diana}

Poster karya Vingka Diana adalah Poster Propaganda. Poster Yang bertujuan untuk Mempengaruhi individu atau sekelompok orang untuk kepentingan tertentu. Dalam karya poster tersebut terdapat gambar sekolah dimana pada saat ini sedang terjadi pandemi sehingga proses belajar mengajar yang terdapat di sekolah di hentikan sejenak dan dilanjutkan di rumah. Hal ini membuat beberapa siswa mengalami kejenuhan dan ingin sekali kembali ke sekolah, belajar seperti sebagaimana biasanya.

\section{(1). Warna dan Tipografi}

Dari hasilpenilaian tentang warna, dapat dikateg orikan sangat baik dengan perolehan nilai 89. Dikatakan sangat baik karena warna yang terdapat pada karya poster tersebut terlihat indah, penuh warna, terdapat gradasi, dan juga teknik yang digunakan yaitu teknik transparan seperti sebagaimana penggunaan cat air. Dari hasil penilaian tentang tipografi, dapat dikategorikan sangat baik dengan perolehan nilai 89 . Tipografi pada karya poster Wisnu Ardana menggunakan klasifikasi jenis font terdiri dari Monotype Corsiva.

\section{KESIMPULAN DAN SARAN}

\section{Kesimpulan}

Hasil penelitian yang telah dilakukan di lapangan berdasarkan uraian yang telah dijabarkan mulai dari latar belakang masalah sampai kepada pembahasan, penulis memperoleh kesimpulan bahwa kemampuan sis wa dalam menggambar dan mewarnai karya poster tergolong baik, siswa mampu memvisualisasikan imajinatif lewat sapuan kuas ke dalam bidang kertas dalam bentuk gambar poster. Pada aspek kemampuan sis wa dalam penerapan tipografi pada karya poster tergolong baik, siswa mampu mengaplikas ikan tulisan dalam poster dengan cukup baik, rapih, dan mudah di mengerti oleh orang yang membacanya sehingga pesannya tersampaikan dengan baik.

Setelah pengumpulan data awal dilaksanakan, pihak sekolah terutama guru seni budaya telah melakukan berbagai upaya untuk meningkatkan nilai hasil belajar
Gorga : Jurnal Seni Rupa

Volume 09 Nomor 02 Juli-Desember 2020 p-ISSN: 2301-5942 | e-ISSN: 2580-2380

sis wa dalam mata pelajaran seni budaya, hal ini terbukti dari hasil penelitian dilapangan yang menunjukkan bahwa nilai seluruh siswa berada di atas Kriteria Ketuntasan Minimal (KKM). Sementara pada waktu pengumpulan data awal, perolehan nilai siswa tergolong rendah dan di bawah KKM.

\section{Saran}

Berdasarkan penelitian yang telah dilakukan, peneliti berharap hasil penelitian ini nantinya dapat menjadi referensi dalam penelitian maupun informasi bagi akademisi dan masyarakat luas. Serta Diharapkan kepada kepala sekolah agar dapat memberikan saran dan motivasi yang baik kepada seluruh siswa agar sis wa mampu mengemban gkan potensi yang ada dalam diri mereka, dan juga dapat memenuhi sarana dan prasarana yang dibutuhkan dalam proses belajar mengajar.

\section{DAFTAR RUJUKAN}

Halawa, W. E., Triy anto, R., Budiwiwaramulja, D., \& Azis, A. C. K. (2020). Analisis Gambar Ilustrasi Hombo Batu Nias Gunungsitoli. Gorga: Jurnal Seni Rupa, 9(1), 193-203.

Kusrianto, A. (2006). Pengantar Desain Komunikasi Visual. Surabaya: Penerbit ANDY Yogyakarta.

Supandi, M. B. (2020). "Kumpulan Karya Poster

Siswa”. Hasil Dokumentasi Pribadi: 10 Agustus 2020, SMK Multimedia Istiqlal Deli Tua.

UUD No. 20 Tahun. (2003). Undang-Undang

20 Tahun 2003 tentang Sistem Pendidikan Nasional.

https://www.jogloabang.com/pustaka/uu-202003-sistem-pendidikan-nasional (diakses tanggal 29 November 2020).

Wibowo, I. (2013). Belajar Desain Grafis. Yogyakarta: Buku Pintar.

Wisnu. (2012). Estetika Poster Ilmiah Fakultas Ilmu Komputer. Semarang: Universitas Dian Nuswantoro. 